\title{
Efficacy of prone position in acute respiratory distress syndrome: overview of systematic reviews
}

\author{
Efetividade da posição prona na síndrome do desconforto \\ respiratório agudo: overview de revisões sistemáticas \\ Efectividad de la posición prona en el síndrome de dificultad \\ respiratoria aguda: overview de revisiones sistemáticas
}

\author{
Michel Marcos Dalmedico ${ }^{1,2}$, Dafne Salas ${ }^{1}$, Andrey Maciel de Oliveira ${ }^{2}$, Fátima Denise Padilha Baran², Jéssica Tereza \\ Meardi ${ }^{1}$, Michelle Caroline Santos ${ }^{2}$
}

How to cite this article:

Dalmedico MM, Salas D, Oliveira AM, Baran FDP, Meardi JT, Santos MC. Efficacy of prone position in acute respiratory distress syndrome: overview of systematic reviews. Rev Esc Enferm USP. 2017;51:e03251. DOI: http://dx.doi.org/10.1590/S1980-220X2016048803251

${ }^{1}$ Universidade Positivo, Curso de Enfermagem, Curitiba, PR, Brazil.

${ }^{2}$ Universidade Federal do Paraná, Programa de Pós-Graduação em Enfermagem, Curitiba, PR, Brazil.

\begin{abstract}
Objective: To identify and integrate the available scientific evidence related to the use of the prone position in patients with acute respiratory distress syndrome for the reduction of the outcome variable of mortality compared to the dorsal decubitus position. Method: Overview of systematic reviews or meta-analyzes of randomized clinical trials. It included studies that evaluated the use of prone positioning in patients with acute respiratory distress syndrome published between 2014 and 2016. The AMSTAR tool was used to determine the methodological quality of studies. The GRADE system was used to establish the overall quality of evidence for the mortality outcome. Results: From the search strategy, were retrieved seven relevant manuscripts of high methodological quality. Conclusion: Scientific evidence supports that combined use of protective ventilatory strategy and prone positioning for periods between 16 and 20 hours in patients with acute respiratory distress syndrome and $\mathrm{PaO} 2 / \mathrm{FiO} 2$ ratio lower than $150 \mathrm{~mm} / \mathrm{Hg}$ results in significant reduction of mortality rate.
\end{abstract}

\section{DESCRIPTORS}

Critical Care; Prone Position; Respiratory Distress Syndrome, Adult; Evidence-Based Nursing; Evidence-Based Practice; Review. 


\section{INTRODUCTION}

Acute Respiratory Distress Syndrome (ARDS) is a potentially devastating form of hypoxemic respiratory failure caused by acute inflammatory lung injury ${ }^{(1)}$. Its characteristics are the sudden onset, presence of a triggering factor (diffuse bilateral pulmonary infiltrate), and normally there is no left heart failure (non-cardiogenic pulmonary edema) or circulatory overload ${ }^{(2)}$.

In 2012, was proposed a new model for the standardization of diagnostic concepts of acute respiratory distress syndrome that took into account the severity of the disease (ARDS Definition Task Force). The name of the recommendation is Berlin Definition, and patients with ARDS are stratified into three categories, namely: mild $\left(\mathrm{PaO}_{2} / \mathrm{FiO}_{2} \leq\right.$ $300 \mathrm{~mm} / \mathrm{Hg}$ with PEEP or CPAP $\geq 5 \mathrm{cmH}_{2} \mathrm{O}$ ); moderate $\left(\mathrm{PaO}_{2} / \mathrm{FiO}_{2} \leq 200 \mathrm{~mm} / \mathrm{Hg}\right.$ with $\left.\mathrm{PEEP} \geq 5 \mathrm{~cm} / \mathrm{H}_{2} \mathrm{O}\right)$; and severe $\left(\mathrm{PaO}_{2} / \mathrm{FiO}_{2} \leq 100 \mathrm{~mm} / \mathrm{Hg} \text { with PEEP }>5 \mathrm{~cm} / \mathrm{H}_{2} \mathrm{O}\right)^{(3)}$.

ARDS is a high incidence phenomenon in the field of intensive care. In this regard, 29,144 patients admitted to intensive care units were evaluated in a multicenter, international and prospective cohort study. It was found that 3,022 patients (10.4\%) met the clinical criteria for ARDS. Of these, 2,377 patients developed the disease within the first 48 hours and required invasive ventilatory support to suppress severe acute respiratory failure. The mortality rate was directly proportional to the severity of disease, as follows: $35 \%$ among patients with mild ARDS, $40 \%$ among patients with moderate ARDS, and $46 \%$ for patients with severe ARDS. Incidence rates of this aggravation in western countries are between $6 \%$ and $7 \%\left({ }^{(4)}\right.$.

Considering the disease relevance in the context of intensive care, clinical diagnosis and the adoption of early therapeutic interventions (specially the use of protective ventilatory strategies) are determinants for reducing morbidity and increasing patients' survival ${ }^{(5)}$.

Thus, ventilatory support is considered the cornerstone of ARDS treatment, despite the changes in the goals of this support in recent years. Such changes prioritize the maintenance of normal physiological parameters to avoid ventilator-induced lung injury and enable proper gas exchange ${ }^{(1)}$.

In patients with hypoxemia refractory to ventilatory support or pulmonary failure $\left(\mathrm{PaO}_{2} / \mathrm{FiO}_{2} \leq 100 \mathrm{~mm} / \mathrm{Hg}\right)$, the use of ventilation in the prone position should be considered. It consists of providing ventilatory support with the patient lying down in ventral decubitus position as additional therapy for the treatment of severe hypoxemia caused by $\operatorname{ARDS}^{(6-7)}$.

By adopting the prone position, the most important physiological effect achieved is significant improvement in oxygenation given the decreased atelectasis, redistribution of alveolar ventilation and perfusion, changes in the conformation of pulmonary structure and diaphragm, and consequent reduction of the gravitational gradient of pleural pressures ${ }^{(8)}$.

Despite the relevance of prone positioning in the treatment of acute respiratory distress syndrome patients, several studies on the subject with publication before 2013 presented unfavorable results regarding the outcome of mortality reduction ${ }^{(7,9-12)}$. In summary, the prone position benefits were limited to $\mathrm{PaO}_{2}$ improvement without direct interference of this phenomenon in reduction of mortality.

In fact, the improvement in oxygenation (increase of at least $20 \%$ in $\mathrm{PaO}_{2} / \mathrm{FiO}_{2}$ ratio or $\geq 20 \mathrm{mmHg}$ in arterial oxygenation) is not directly associated with a reduction in overall mortality rates. This suggests that oxygenation itself is not determinant in improved survival of patients submitted to ventilation in the prone position ${ }^{(13)}$.

This panorama underwent substantial changes after publication of the PROSEVA study, a randomized multicenter clinical trial of 466 individuals with $\mathrm{ARDS}, \mathrm{PaO}_{2} / \mathrm{FIO}_{2}$ $<150 \mathrm{~mm} / \mathrm{Hg}$, and ventilatory support ( $\mathrm{PEEP} \geq 5 \mathrm{~cm} \mathrm{H}_{2} \mathrm{O}$, $\mathrm{F}_{\mathrm{I}} \mathrm{O}_{2} \geq 0.6$ ). The results showed that early use (between 12 and 24 hours after ARDS diagnosis) of prone position for a prolonged time significantly reduced mortality in the intervention group. Mortality at 28 days was $16 \%$ in the prone position group and $32.8 \%$ in the control group $(\mathrm{P}<0.001)$, and at 90 days, it was $23.6 \%$ in the intervention group versus $41.0 \%$ in the supine group $(\mathrm{P}<0.001)^{(14)}$.

ARDS is one of the most important clinical illness of modern intensive medicine because of its high rates of incidence, mortality and long-term sequelae in survivors ${ }^{(15)}$, and patients usually have longer hospitalizations and greater consumption of resources, resulting in increased hospital costs. These facts justify the development of the present study.

Therefore, when considering a synthesis that integrates the evidence found in systematic reviews, the present study may contribute to identify the gaps in this topic, support the development of future research, and guide clinical practice based on evidence. The aim of the study is to identify and integrate the available scientific evidence related to the use of prone positioning in patients with acute respiratory distress syndrome for reduction of the outcome variable of mortality, when compared to dorsal decubitus.

\section{METHOD}

This is an overview of systematic reviews of randomized clinical trials based on the Cochrane Handbook for Systematic Reviews of the recommendations of Interventions. The Overview is a study design that integrates and synthesizes information from existing systematic reviews on a particular topic from the analysis of interventions available for a treatment or prevention of this clinical condition. Its aim is to provide an expanded view of multiple revisions of interventions that address the effects of two or more potential interventions for a single health condition or problem in order to identify the effects and trends of the studied variables ${ }^{(16)}$.

The identification and evaluation process of all published reviews allows that researchers describe the quality of this evidence base, summarize and compare the study findings, and discuss their strength.

The elaboration of the research question to guide the scope of the study was based on the domains of the PICOS acronym $(\mathrm{P}$ - population or problem, $\mathrm{I}$ - intervention, $\mathrm{C}-$ comparison, $\mathrm{O}$ - outcomes, $\mathrm{S}$ - Study design), in which: $\mathrm{P}$ - Patients with acute respiratory distress syndrome (moderate or severe); I - Use of prone positioning; C - Dorsal decubitus; $\mathrm{O}$ - reduction of mortality; $\mathrm{S}$ - Systematic review 
or meta-analysis. Thus, the research question structured was: What is the efficacy of the prone position in mortality reduction in patients with moderate or severe acute respiratory distress syndrome in ventilatory support when compared to the use of dorsal decubitus position?

The eligibility criteria were the systematic reviews with meta-analysis published between 2014 and 2016 that included the use of prone positioning in the treatment of acute respiratory distress syndrome. The temporal cut is explained by the publication of results obtained in the PROSEVA trial ${ }^{(14)}$. The findings of such study demonstrated a left-hand deviation in forest plot graphs, showing the prone position as an intervention that could be associated with better mortality outcomes. Only articles in English were chosen for the selection of secondary studies.

Descriptors and their synonyms in English were used in the search for secondary studies in the previously established databases: Medical Subject Headings (MeSH) - Prone Position; Acute Respiratory Distress Syndrome. In addition, were defined the following types of study: Systematic
Review or Meta-analysis. Descriptors and terms related to the research problem (acute respiratory distress syndrome), intervention (prone position) and study design (systematic review or meta-analysis) were used. The terms combined by means of Boolean operators AND, OR, added to truncation symbols formed the basis of the search equation, later adapted to specifications of each base.

The relevant studies were retrieved through searches in the following electronic databases: Medical Literature Analysis and Retrieval System Online/Pubmed (MEDLINE), Cochrane Central Register of Controlled Trials (CENTRAL) and Cumulative Index to Nursing \& Allied Health Literature (CINAHL). The last search update was made in September 2016. The search strategies were formulated according to the criteria and manuals of each database (Chart 1). In addition, was performed a manual search for relevant studies not indexed in the databases, such as research reports from academic and non-academic institutions, government agency documents, theses, dissertations, and other publications known as 'gray literature'.

Chart 1 - Search strategies and respective bases.

\begin{tabular}{|c|c|}
\hline Base & Search strategy \\
\hline MEDLINE/PUBMED & $\begin{array}{l}\text { SEARCH \#1 (((("Prone Position" [MeSH Terms]) OR Prone Position [Title/Abstract]) OR Prone Positioning [Title/ } \\
\text { Abstract]) OR Prone Positions [Title/Abstract]) } \\
\text { SEARCH \#2 (((("Respiratory Distress Syndrome, Adult" [MeSH Terms] OR "Respiratory Distress Syndrome, } \\
\text { Adult"[Title/Abstract]) OR Acute Respiratory Distress Syndrome" [MeSH Terms]) OR Acute Respiratory Distress } \\
\text { Syndrome[Title/Abstract]) } \\
\text { SEARCH \#3 ((((Systematic Review [Publication Type]) OR Systematic Review [Title/Abstract]) OR Meta-analysis } \\
\text { [MeSH Terms]) OR Meta-analysis [Title/Abstract]) } \\
\text { SEARCH \#4 = \#1 AND \#2 AND \#3 } \\
\text { SEARCH \#5 prone posit\$.mp. } \\
\text { SEARCH \# } 6 \text { = \#4 AND \#5 }\end{array}$ \\
\hline Cochrane CENTRAL & $\begin{array}{l}\text { SEARCH \#1 (ARDS or acute respiratory distress syndrome or adult respiratory distress syndrome) } \\
\text { SEARCH \#2 ("Prone Position" OR "Prone Positioning") } \\
\text { SEARCH \#3 ("Systematic Review" OR "Meta-analysis"). } \\
\text { SEARCH \#4 = \#1 AND \#2 AND \#3 } \\
\text { Limiters - Date of publication: } 2014-2016\end{array}$ \\
\hline CINAHL & $\begin{array}{l}\text { SEARCH ("Prone Position" OR “Prone Positioning") AND ("Acute Respiratory Distress Syndrome" OR "ARDS") } \\
\text { AND ("Systematic Review" OR “Meta-analysis"). } \\
\text { Limiters - Date of publication: 2014-2016 }\end{array}$ \\
\hline
\end{tabular}

Source: Prepared by the authors.

The selection of systematic reviews (SR), data extraction and qualitative evaluations were performed in duplicate. The inclusion process had two phases: a) first screening - evaluation of titles and abstracts of all identified studies; $b$ ) reading in full - evaluation of the full text. In the first consensus meeting, the previously selected studies were evaluated in full with application of the eligibility criteria. In the second consensus meeting, were defined the studies included and excluded from the review to compose the final sample. The Kappa coefficient was applied to determine agreement between evaluators, and scores ranged from 1 (complete agreement) to -1 (complete disagreement). In consensus meetings, there was support from a third reviewer for cases of disagreement. The results obtained were organized in a narrative summary (Chart 2).

All the included studies were evaluated with the AMSTAR tool (Assessing the Methodological Quality of Systematic Reviews) to determine the methodological quality of systematic reviews. A score was assigned to each SR from the sum of all positive responses to the questionnaire items. The included reviews were classified as follows: scores between 8-11 were considered as high quality, scores 4-7 were average quality, and scores 0-3 were considered as low quality. In cases of studies with low AMSTAR scores, were 
performed sensitivity analyzes to determine the potential risk of bias.

The overall quality of the evidence for the studied outcome was assessed using the GRADE system (Grading of Recommendations Assessment, Development and Evaluation). This approach identifies four elements that influence the quality of evidence: study design, study quality (risk of bias), consistency (comparison of effect estimates across studies), and direction (applicability of participants, interventions, and outcomes for the clinical issue in consideration). Evaluating and combining these components determines the initial quality of evidence as:

High: further research is very unlikely to change confidence on the effect estimate.

Moderate: further studies are likely to have a significant impact on the confidence of the effect estimate and may alter this estimate.

Low: other studies are likely to have a significant impact on the confidence of the effect estimate and to change the estimate.

Very low: any estimate of effect is very uncertain.

The use of the GRADE system requires a clear definition of population, intervention, comparison, and studied outcomes (PICO) to determine the strength of evidence.

Thus, the GRADE system was applied to the following outcome measures: adult participants with severe hypoxemia; mechanical ventilation with lower tidal volumes; maintenance of the prone position for 16 or more hours per day.

There was no conflict of interest and no type of funding involved in the performance of this review.

\section{RESULTS}

Systematic reviews and meta-analyzes of randomized controlled trials comparing the effects of prone position (intervention) and dorsal decubitus position (control) in patients with moderate or severe acute respiratory distress syndrome were included. The search strategies resulted in 26 studies. Of these, two were published in two electronic databases. After the first selection phase (screening), 17 studies were excluded because they did not meet the study objective nor answer the guiding question.

Thus, after independent analysis by two reviewers, seven studies were evaluated in full and met the eligibility criteria therefore, they composed the final sample of this review (Figure 1). The Kappa score among observers regarding the inclusion or exclusion of studies was $0.517(\mathrm{p}=<0.004)$.
Divergences were resolved with intervention of a third reviewer at a second consensus meeting.

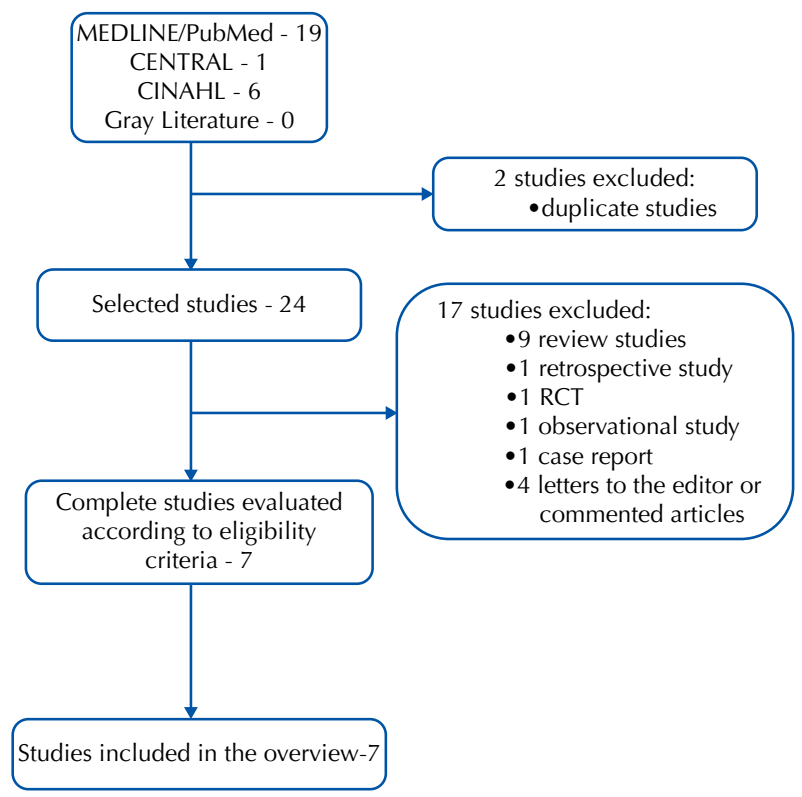

Figure 1 - Flowchart for identification, selection and inclusion of studies - Curitiba, Paraná, Brazil, 2017.

Chart 2 presents the selected studies with the respective references, year of publication, number of patients evaluated, analyzed outcome and main results obtained.

The present study included clinical trials on the use of prone position in different periods of time, patients with moderate or severe ARDS, and low $(<6 \mathrm{ml} / \mathrm{kg})$ or high $(>6 \mathrm{ml} / \mathrm{kg}$ ) tidal volumes. The analysis of these elements was adjusted in subgroups according to the identified heterogeneity.

Stratification by tidal volume accounted for more than half of heterogeneity among the randomized clinical trials observed in the non-stratified analysis of the sample ${ }^{(17)}$. Table 1 demonstrates the most significant relative risk was found for the 60-day hospitalization period in the conditions under study ${ }^{(18)}$. Statistical significance for the reduction of mortality from prone positioning was verified in six out of the 11 studies included, especially in those in which protective ventilation was used ${ }^{(19)}$. The results were more favorable to the long-term prone position (= to or > 90 days $)^{(21)}$. There was statistical significance in the reduction of mortality when performing the adjusted analysis for lower tidal volume ${ }^{(23)}$.

Chart 2 - Main characteristics of included studies.

\begin{tabular}{|c|c|c|c|}
\hline Study & $\mathrm{N}$ (Clinical trial/Patients) & Outcomes & Main findings \\
\hline Beitler et al. $2014^{(17)}$ & Seven clinical trials $(\mathrm{N}=2,119)$. & Risk of death within 60 days & $\begin{array}{l}\text { When stratified by high or low tidal volume, randomized } \\
\text { clinical trials combining prone positioning and protective } \\
\text { ventilatory strategy (reduced volumes) showed a } \\
\text { significant decrease in the risk of death }(\mathrm{p}=0.002) \text {. }\end{array}$ \\
\hline Hu et al. $2014^{(18)}$ & $\begin{array}{l}\text { Nine clinical trials }(\mathrm{N}=2,242 \\
\text { patients). }\end{array}$ & Mortality at 30,60 and 90 days & $\begin{array}{l}\text { Compared to the supine position, the prone position } \\
\text { reduced mortality at } 30(p=0.003), 60(p=0.04) \text { and } 90 \\
\text { days }(0.0001) \text { in patients with severe ARDS. Length of } \\
\text { stay longer than } 12 \text { daily hours in the prone position } \\
\text { contributes to mortality reduction }(p=0.04) \text {. }\end{array}$ \\
\hline
\end{tabular}

continued... 


\begin{tabular}{|c|c|c|c|}
\hline Study & $\mathrm{N}$ (Clinical trial/Patients) & Outcomes & Main findings \\
\hline Sud et al. 2014 & $\begin{array}{l}11 \text { randomized clinical trials } \\
\qquad(\mathrm{N}=2,341)\end{array}$ & Mortality from any cause & $\begin{array}{l}\text { The analysis of high quality evidence showed that prone } \\
\text { positioning during mechanical ventilation reduces } \\
\text { mortality among ARDS patients who receive protective } \\
\text { lung ventilation (reduced tidal volumes) when compared } \\
\text { to the use of high tidal volumes or supine positioning. }\end{array}$ \\
\hline Lee et al. 2014 (20) & $\begin{array}{l}11 \text { randomized clinical trials } \\
\qquad(\mathrm{N}=2,246)\end{array}$ & Mortality & $\begin{array}{l}\text { The reduction in overall mortality was significantly higher } \\
\text { in the intervention group }(p=0.039) \text {. These results were } \\
\text { higher in the subgroup in which duration of ventilation } \\
\text { in prone position was greater than } 10 \text { hours/session } \\
\text { compared to the subgroup with shorter duration }(p=0.039) \text {. }\end{array}$ \\
\hline $\begin{array}{l}\text { Bloomfield et al. } \\
\qquad 2014^{(21)}\end{array}$ & $\begin{array}{c}\text { Nine clinical trials } \\
(\mathrm{N}=2,149 \text { individuals })\end{array}$ & Short and long-term mortality & $\begin{array}{l}\text { In the subgroups: recruited within } 48 \text { hours, treated } \\
\text { in prone position for } 16 \text { or more hours per day, and } \\
\text { participants with more severe hypoxemia, there were } \\
\text { statistically significant results for the outcome of } \\
\text { mortality reduction. }\end{array}$ \\
\hline Park et al. 2015 (22) & $\begin{array}{l}\text { Eight randomized clinical trials } \\
\qquad(N=2,141 \text { patients). }\end{array}$ & Mortality & $\begin{array}{l}\text { Mortality rates were lower in the intervention group } \\
\text { compared to the control group }(41 \% \text { and } 47 \% \text {, } \\
\text { respectively). In the subgroups of mechanical ventilation } \\
\text { with protective strategy and duration of prone positioning } \\
\text { greater than } 12 \text { hours, mortality rates were significantly } \\
\text { reduced ( } p=0.0002 \text { and } p<0.0001 \text {, respectively). }\end{array}$ \\
\hline $\begin{array}{l}\text { Mora-Arteaga et al. } \\
\qquad 2015^{(23)}\end{array}$ & $\begin{array}{l}\text { Seven blind controlled studies } \\
\qquad(N=2,119 \text { patients). }\end{array}$ & Reduced risk of death & $\begin{array}{l}\text { When patients submitted to the prone position were } \\
\text { stratified by subgroups, there was a significant decrease } \\
\text { in mortality risk in ventilated patients with low tidal } \\
\text { volume, the first } 48 \text { hours of disease evolution, and } \\
\text { severe hypoxemia. }\end{array}$ \\
\hline
\end{tabular}

Source: Prepared by the authors.

Table 1 - Measures of effect of the PRONE position in reducing the mortality of patients with ARDS compared to the supine position - Curitiba, Paraná, Brazil, 2017.

\begin{tabular}{|c|c|c|c|c|c|c|c|}
\hline \multirow{2}{*}{ Study } & \multirow{2}{*}{ Sample size } & \multicolumn{2}{|c|}{ Allocation } & \multirow{2}{*}{ R.R. } & \multirow{2}{*}{ O.R. } & \multirow{2}{*}{ C.I. $(95 \%)$} & \multirow{2}{*}{ p-value } \\
\hline & & Prone position & Supine position & & & & \\
\hline Beitler et al., 2014(17) & 2,119 & 1,088 & 1,031 & 0.83 & & $(0.68-1.02)$ & 0.002 \\
\hline Hu et al., 2014 ${ }^{(18)}$ & 2,242 & 1,150 & 1,092 & 0.82 & & $(0.68-0.99)$ & 0.004 \\
\hline $\operatorname{Sud}^{(19)}$ & 1,016 & 510 & 506 & 0.74 & & $(0.59-0.95)$ & \\
\hline $\mathrm{Lee}^{(20)}$ & 2,246 & 1,142 & 1,104 & & 0.77 & $(0.59-0.99)$ & 0.039 \\
\hline Bloofield $^{(21)}$ & 2,165 & 1,107 & 1,041 & 0.86 & & $(0.72-1.03)$ & \\
\hline Park $^{(22)}$ & 2,141 & 1,099 & 1,042 & 0.90 & & $(0.82-0.98)$ & 0.02 \\
\hline Mora-Arteaga $^{(23)}$ & 2,119 & 1,088 & 1,031 & & 0.76 & $(0.54-1.06)$ & \\
\hline
\end{tabular}

Source: Prepared by the authors.

\section{DISCUSSION}

Assuming that mortality outcome is critical for decision making, the aim of this study was to identify and integrate the main available scientific evidence related to the use of prone position compared to dorsal decubitus position in patients with acute respiratory distress syndrome for the outcome variable of reduction in mortality. Prone positioning has been widely used as a therapeutic resource in clinical practice, hence high-quality scientific basis is fundamental to support its indication. Seven high-quality meta-analyzes were analyzed, all of which evaluated the prone position as an intervention. They all included 14 randomized clinical trials with 2,372 patients with moderate or severe ARDS randomly distributed (intervention and control) for the outcome of mortality reduction.

The mean methodological quality of the analyzed systematic reviews was $9.71(\mathrm{SD}=0.76)$, with $95 \%$ confidence interval between 9.15 and 10.27. This leads to the conclusion that the systematic reviews included have high scientific rigor when assessing the maximum AMSTAR score (11 points). Considering the elements of the AMSTAR measuring tool, all the included studies described the following: clinical question and inclusion criteria; selection and data extraction by peers; conduction of a comprehensive literature survey; list of studies (included and excluded); characteristics of the included studies; assessment of the scientific quality of included studies; the use of the scientific quality of studies in the formulation of conclusions; appropriate combination of study results; risk assessment of bias.

The search for relevant studies in gray literature was not contained in the inclusion criteria of three systematic reviews ${ }^{(17-18,23)}$. Six studies did not state the conflicts of interest ${ }^{(17-20,22-23)}$.

The quality of evidence reported by the primary studies in the included reviews was assessed using the GRADE method, and considered moderate for the following subgroups: rapid intervention, severe hypoxemia and protective ventilation. These data are compatible with the findings of a Cochrane systematic review ${ }^{(21)}$.

Despite the impossibility of blinding (concealment) the intervention (prone position), when the overall mortality 
outcome is analyzed, masking is irrelevant. The researcher's knowledge about which treatment the patient underwent would not imply the inadequate classification of this outcome.

Regarding the studied intervention, a meta-analysis with nine clinical trials maintains there is no convincing evidence of the beneficial or detrimental effect of the universal application of prone positioning in adults with hypoxemia under mechanical ventilatory support. However, when analyzing three distinct subgroups, namely: implementation of the prone position within 48 hours of disease course; prone position for 16 or more hours per day; and more severe hypoxemia, statistically significant benefits in reduction of mortality were obtained when using the prone position ${ }^{(21)}$.

The early use of prone position during ventilatory support for severe acute respiratory distress syndrome in patients requiring relatively high PEEP levels and reduced tidal volumes is associated with the best physiological response of collapsed alveolar units. As these units are more susceptible to be open (alveolar recruitment) during the initial phase of disease (exudative), it implies on a significant reduction in mortality ${ }^{(14,18,23)}$. Another relevant aspect of using the prone position refers to the analysis of the subgroup ${ }^{~} \mathrm{PaO} 2 / \mathrm{FiO} 2$ ratio' that indicated a significant reduction in the additional mortality rate in patients with severe hypoxemia or other severe clinical conditions associated ${ }^{(14)}$. Severely hypoxemic patients appear to respond better to the intervention.

Mortality reduction is related to the overall effects of prone positioning, such as hemodynamic improvement in gas exchange (optimization of alveolar recruitment, perfusion and ventilation) and respiratory mechanics. There is also reduction of deleterious effects caused by mechanical ventilation-induced lung injury given the homogenization of stress and tension on the pulmonary parenchyma ${ }^{(23-24)}$, allowing a reduction in $\mathrm{FIO}_{2}$ values and lower airway pressure to obtain adequate oxygenation ${ }^{(25)}$.

Another important fact is the tidal volume used during ventilatory support. A randomized study showed that lower tidal volume $(6 \mathrm{ml} / \mathrm{kg}$ of predicted weight) resulted in decreased mortality ( $31 \%$ versus $39.8 \%, \mathrm{P}=0.007)$ and reduction in days of ventilatory support $(\mathrm{P}=0.007)$, when compared to the use of ventilation strategy with high tidal volume $^{(13)}$. Ventilatory strategies associating low tidal volumes and pressure-volume $(\mathrm{P}-\mathrm{V})$ relationship guided by PEEP static curve, FiO2-guided, high PEEP, and proneposition ventilation are potentially the best alternative for ventilatory support in terms of improved survival in patients with moderate or severe $\operatorname{ARDS}^{(26)}$.

Although tidal volume is an important determinant of mortality reduction, a meta-analysis of approximately 2,000 patients has shown reductions in tidal volume or increases in PEEP are beneficial only if associated with maintaining driving pressure (difference between plateau pressure and PEEP) lower than $16 \mathrm{cmH}_{2} \mathrm{O}$. Driving pressure was pointed out as the main variable determining the best prognosis for the mortality outcome in patients with moderate or severe $\operatorname{ARDS}^{(27)}$.

In summary, under specific conditions and indications, prone position ventilation is a feasible, safe and inexpensive therapy ${ }^{(28)}$ that improves alveolar gas exchange in more than two thirds of patients with severe acute respiratory failure $^{(29)}$. Prone positioning is a viable maneuver for most intensive care units, and its application should be part of the institutional protocol because it requires trained personnel, who consider the particularities of each service and each patient ${ }^{(30)}$.

\section{CONCLUSION}

By analyzing the results obtained, this overview provides consistent scientific evidence on the incorporation of use of the prone position in patients with acute respiratory distress syndrome. The use of ventilatory interventions such as lower tidal volumes and high PEEP associated with adjuvant therapies such as prone positioning in patients with severe acute hypoxemic respiratory failure results in a significant reduction in overall mortality. The intervention efficacy was statistically significant in three subgroups: rapid implementation of the prone position ( $<48$ hours of disease course); prolonged stay in ventral decubitus position ( $>16$ consecutive hours); and severe hypoxemia $\left(\mathrm{PaO}_{2} / \mathrm{FiO}_{2}<150 \mathrm{~mm} / \mathrm{Hg}\right)$.

Thus, the available scientific evidence suggests that early combination of using protective ventilatory strategy with a sustained driving pressure of less than $16 \mathrm{cmH} 2 \mathrm{O}$ and prone positioning for periods of 16 to 20 hours in patients with severe acute respiratory distress syndrome results in benefits on mortality reduction.

The rigorous search for studies with high scientific and methodological quality and careful analysis of their findings corroborate the expressiveness of the evidence obtained, and demonstrate the scientific findings that can be incorporated into clinical practice.

In view of the above, this study supports the use of prone positioning in clinical practice of intensive care units. Moreover, for the effective benefit of patients with acute respiratory distress syndrome from use of the prone position, it is imperative that the production of scientific evidence is complemented by highly trained professionals involved in the care, and who understand the clinical dimensions and practices of this intervention for the promotion of a safer and evidence-based bedside service.

Objetivo: Identificar e integrar as evidências científicas disponíveis relacionadas à utilização da posição prona em pacientes com síndrome do desconforto respiratório agudo para a redução da variável de desfecho mortalidade, quando comparada ao decúbito dorsal. Método: Overview de revisões sistemáticas ou metanálises de ensaios clínicos randomizados. Foram incluídos estudos publicados no período entre 2014 e 2016, que avaliaram a utilização de posição prona em pacientes com síndrome do desconforto respiratório agudo. 
Utilizou-se da ferramenta AMSTAR para determinar a qualidade metodológica dos estudos e o sistema GRADE para estabelecer a qualidade geral da evidência para o desfecho mortalidade. Resultados: A partir da estratégia de busca foram recuperados sete manuscritos relevantes de alta qualidade metodológica. Conclusão: As evidências científicas sustentam que a utilização combinada de estratégia ventilatória protetora e posição prona por períodos entre 16 e 20 horas em pacientes com síndrome do desconforto respiratório agudo, com relação $\mathrm{PaO} 2 / \mathrm{FiO} 2$ inferior à $150 \mathrm{~mm} / \mathrm{Hg}$, resulta em redução significativa da taxa de mortalidade.

\section{DESCRITORES}

Cuidados Críticos; Decúbito Ventral; Síndrome do Desconforto Respiratório do Adulto; Enfermagem Baseada em Evidências; Prática Clínica Baseada em Evidências; Revisão.

\section{RESUMEN}

Objetivo: Identificar e integrar las evidencias científicas disponibles relacionadas con la utilización de la posición prona en pacientes con síndrome de dificultad respiratoria aguda para la reducción de la variable de resultado mortalidad, cuando comparado al decúbito dorsal. Método: Panorama de revisiones sistemáticas o metaanálisis de ensayos clínicos randomizados. Fueron incluidos estudios publicados en el período entre 2014 y 2016, que evaluaron la utilización de posición prona en pacientes con síndrome de dificultad respiratoria aguda. Se utilizó la herramienta AMSTAR para determinar la calidad metodológica de los estudios y el sistema GRADE para establecer la calidad general de la evidencia para el resultado mortalidad. Resultados: A partir de la estrategia de búsqueda fueron recuperados siete manuscritos relevantes de alta calidad metodológica. Conclusión: Las evidencias científicas sostienen que la utilización combinada de estrategia ventilatoria protectora y posición prona por períodos entre 16 y 20 horas en pacientes con síndrome de dificultad respiratoria aguda, con relación $\mathrm{PaO} 2 / \mathrm{FiO} 2$ inferior a $150 \mathrm{~mm} / \mathrm{Hg}$, resulta en reducción significativa de la tasa de mortalidad.

\section{DESCRIPTORES}

Cuidados Críticos; Posición Prona; Síndrome de Dificultad Respiratoria del Adulto; Enfermería Basada en la Evidencia; Práctica Clínica Basada en la Evidencia; Revisión.

\section{REFERENCES}

1. Silversides JA, Ferguson ND. Clinical review: acute respiratory distress syndrome - clinical ventilator management and adjunct therapy. Crit Care [Internet]. 2013 [cited 2016 Jan 13];17(2):225. Available from: https://www.ncbi.nlm.nih.gov/pmc/articles/PMC3672489/

2. Barbas CS, Isola AM, Caser EB. What is the future of acute respiratory distress syndrome after the Berlin definition? Curr Opin Crit Care. 2014;20(1):10-6.

3. ARDS Definition Task Force, Ranieri VM, Rubenfeld GD, Thompson BT, Ferguson ND, Caldwell E, Fan E, et al. Acute respiratory distress syndrome: the Berlin Definition. JAMA. 2012;307(23):2526-33.

4. Bellani G, Laffey JG, Pham T, Fan E, Brochard L, Esteban A, et al. Epidemiology, patterns of care, and mortality for patients with acute respiratory distress syndrome in Intensive Care Units in 50 countries. JAMA 2016;315(8):788-800.

5. Papazian L, Forel JM, Gacouin A, Penot-Ragon C, Perrin G, Loundou A, et al. Neuromuscular blockers in early acute respiratory distress syndrome. N Engl J Med. 2010;363(12):1107-16.

6. Matthay MA, Ware LB, Zimmerman GA. The acute respiratory distress syndrome. J Clin Invest [Internet]. 2012 [cited 2016 May 11]:122(8):2731-40. Available from: https://www.ncbi.nlm.nih.gov/pmc/articles/PMC3408735/

7. Sud S, Friedrich JO, Taccone P, Polli F, Adhikari NK, Latini R, et al. Prone ventilation reduces mortality in patients with acute respiratory failure and severe hypoxemia: systematic review and meta-analysis. Intensive Care Med. 2010;36(4):585-99.

8. Seguras Llanes O, Yora Orta, R, Gutiérrez Gutiérrez, L, García Gómez, A. Ventilación prona en pacientes con daño pulmonar agudo ingresados en cuidados intensivos. Rev Cuba Anestesiol Reanim [Internet]. 2011 [citado 2016 Abr 23]; 10(1): 43-51. Disponible en: http:// bvs.sld.cu/revistas/scar/vol_10_1_11/ane06111.htm

9. Curley MA. Prone positioning of patients with acute respiratory distress syndrome: a systematic review. Am J Crit Care. 1999;8(6):397-405.

10. Mebazaa MS, Abid N, Frikha N, Mestiri T, Ben Ammar MS. The prone position in acute respiratory distress syndrome: a critical systematic review. Ann Fr Anesth Reanim. 2007;26(4):307-18.

11. Kopterides P, Siempos II, Armaganidis A. Prone positioning in hypoxemic respiratory failure: meta-analysis of randomized controlled trials. J Crit Care. 2009;24(1):89-100.

12. Sud S, Sud M, Friedrich JO, Adhikari NK. Effect of mechanical ventilation in the prone position on clinical outcomes in patients with acute hypoxemic respiratory failure: a systematic review and meta-analysis. CMAJ [Internet]. 2008 [cited 2016 Apr 23]:178(9):1153-61 Available from: https://www.ncbi.nlm.nih.gov/pmc/articles/PMC4081236/

13. The Acute Respiratory Distress Syndrome Network, Brower RG, Matthay MA, Morris A, Schoenfeld D, Thompson BT, Wheeler A. Ventilation with lower tidal volumes as compared with traditional tidal volumes for acute lung injury and the acute respiratory distress syndrome. $\mathrm{N}$ Engl J Med [Internet]. 2000 [cited 2016 July 23];342(18):1301-8. Available from: http://www.nejm.org/doi/full/10.1056/NEJM200005043421801

14. Guérin C, Reignier J, Richard JC, Beuret P, Gacouin A, Boulain T, et al. PROSEVA Study Group. Prone positioning in severe acute respiratory distress syndrome. N Engl J Med [Internet]. 2013 [cited 2016 May 10];368(23):2159-68. Available from: http://www.nejm.org/ doi/full/10.1056/NEJMoa1214103

15. Cardinal-Fernández P, Correger E, Villanueva J, Rios F. Acute respiratory distress: from syndrome to disease. Med Intensiva. 2016;40(3):16975.

16. Becker LA, Oxman AD. Overviews of reviews. In: Higgins JPT, Green S, editors. Cochrane Handbook for Systematic Review of Interventions. Version 5.1.0 [Internet]. Oxford: The Cochrane Library; 2011 [cited 2016 Jan 10]. Available from: http://handbook.cochrane.org/ 
17. Beitler JR, Shaefi S, Montesi SB, Devlin A, Loring SH, Talmor D, et al. Prone positioning reduces mortality from acute respiratory distress syndrome in the low tidal volume era: a meta-analysis. Intensive Care Med [Internet]. 2014 [cited 2016 June 23]:40(3):332-41. Available from: https://www.ncbi.nlm.nih.gov/pmc/articles/PMC3976426/

18. Hu SL, He HL, Pan C, Liu AR, Liu SQ, Liu L, et al. The effect of prone positioning on mortality in patients with acute respiratory distress syndrome: a meta-analysis of randomized controlled trials. Crit Care [Internet]. 2014 [cited 2016 June 12]:28;18(3):R109. Available from: https://www.ncbi.nlm.nih.gov/pmc/articles/PMC4075407/

19. Sud S, Friedrich JO, Adhikari NK, Taccone P, Mancebo J, Polli F, et al. Effect of prone positioning during mechanical ventilation on mortality among patients with acute respiratory distress syndrome: a systematic review and meta-analysis. CMAJ [Internet]. 2014 [cited 2016 July 10];186(10):E381-90. Available from: https://www.ncbi.nlm.nih.gov/pmc/articles/PMC4081236/

20. Lee JM, Bae W, Lee YJ, Cho YJ. The efficacy and safety of prone positional ventilation in acute respiratory distress syndrome: updated studylevel meta-analysis of 11 randomized controlled trials. Crit Care Med [Internet]. 2014 [cited 2016 May 05];42(5):1252-62. Available from: https://www.ncbi.nlm.nih.gov/pubmedhealth/PMH0061924/

21. Bloomfield R, Noble DW, Sudlow A. Prone position for acute respiratory failure in adults. Cochrane Database Syst Rev. 2015 ;(11):CD008095.

22. Park SY, Kim HJ, Yoo KH, Park YB, Kim SW, Lee SJ, et al. The efficacy and safety of prone positioning in adults patients with acute respiratory distress syndrome: a meta-analysis of randomized controlled trials. J Thorac Dis [Internet]. 2015 [cited 2016 June 21];7(3): 356-367. Available from: https://www.ncbi.nlm.nih.gov/pmc/articles/PMC4387391/

23. Mora-Arteaga JA, Bernal-Ramírez OJ, Rodríguez SJ. The effects of prone position ventilation in patients with acute respiratory distress syndrome: a systematic review and metaanalysis. Med Intensiva. 2015;39(6):359-72.

24. Koulouras V, Papathanakos G, Papathanasiou A, Nakos G. Efficacy of prone position in acute respiratory distress syndrome patients: a pathophysiology-based review. World J Crit Care Med [Internet]. 2016 [cited 2016 July 01];5(2):121-36. Available from: http://www.ncbi. nlm.nih.gov/pmc/articles/PMC4848155/

25. Gattinoni L, Pesenti A, Carlesso E. Body position changes redistribute lung computed-tomographic density in patients with acute respiratory failure: impact and clinical fallout through the following 20 years. Int Care Med. 2013;39(11):1909-15.

26. Wang C, Wang X, Chi C, Guo L, Guo L, Zhao N, et al. Lung ventilation strategies for acute respiratory distress syndrome: a systematic review and network meta-analysis. Sci Rep [Internet]. 2016 [cited 2016 Jul 11];6:22855. Available from: http://www.ncbi.nlm.nih.gov/ pmc/articles/PMC4783789/

27. Amato MBP, Meade MO, Slutsky AS, Brochard L, Costa ELV, Schoenfeld DA, et al. Driving pressure and survival in the acute respiratory distress syndrome. N Engl J Med [Internet]. 2015 [cited 2016 May 23];372(8):747-55. Available from: http://www.nejm.org/doi/full/10.1056/ NEJMsa1410639\#t=article

28. Agrawal SP, Goel AD. Prone position ventilation in Acute Respiratory Distress Syndrome: an overview of the evidences. Indian J Anaesth [Internet]. 2015 [cited 2016 July 30];59(4):246-8. Available from: https:/www.ncbi.nlm.nih.gov/pmc/articles/PMC4408655/

29. Cornejo R, Romero C, Ugalde D, Bustos P, Diaz G, Galvez R, et al. High-volume hemofiltration and prone ventilation in subarachnoid hemorrhage complicated by severe acute respiratory distress syndrome and refractory septic shock. Rev Bras Ter Intensiva [Internet]. 2014 [cited 2016 July 13];26(2):193-9. Available from: https://www.ncbi.nlm.nih.gov/pmc/articles/PMC4103947/

30. Setten M, Plotnikow GA, Accoce M. Prone position in patients with acute respiratory distress syndrome. Rev Bras Ter Intensiva [Internet]. 2016 [cited 2017 Mar 03]; 28(4):452-62. Available from: https://www.ncbi.nlm.nih.gov/pmc/articles/PMC5225921/ 